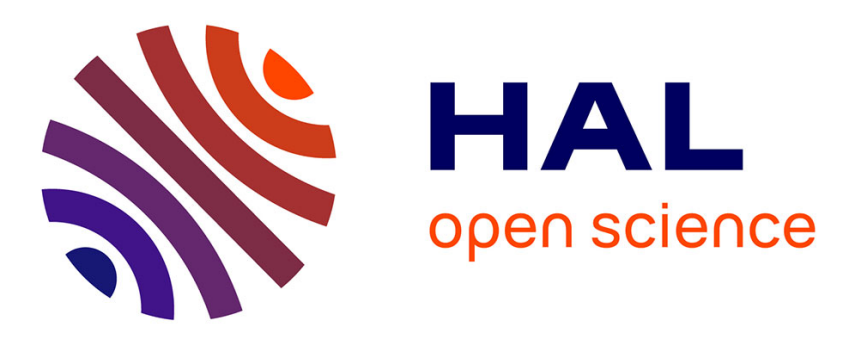

\title{
Diffusion, Drift and their interrelation through Volume Density
}

\author{
Marek Danielewski, Bartek Wierzba
}

\section{To cite this version:}

Marek Danielewski, Bartek Wierzba. Diffusion, Drift and their interrelation through Volume Density. Philosophical Magazine, 2009, 89 (04), pp.331-348. 10.1080/14786430802620732 . hal-00514006

\section{HAL Id: hal-00514006 https://hal.science/hal-00514006}

Submitted on 1 Sep 2010

HAL is a multi-disciplinary open access archive for the deposit and dissemination of scientific research documents, whether they are published or not. The documents may come from teaching and research institutions in France or abroad, or from public or private research centers.
L'archive ouverte pluridisciplinaire HAL, est destinée au dépôt et à la diffusion de documents scientifiques de niveau recherche, publiés ou non, émanant des établissements d'enseignement et de recherche français ou étrangers, des laboratoires publics ou privés. 


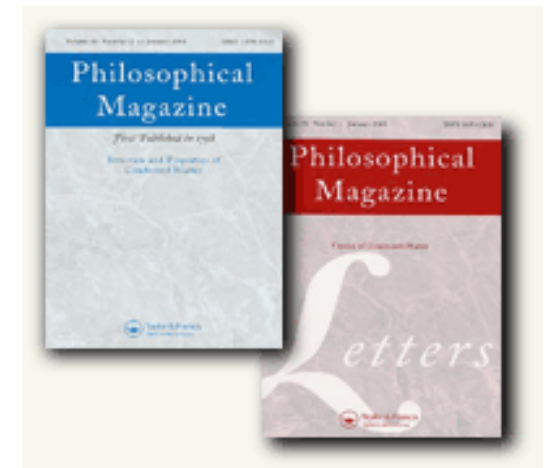

\section{Diffusion, Drift and their interrelation through Volume Density}

\begin{tabular}{|c|c|}
\hline Journal: & Philosophical Magazine \& Philosophical Magazine Letters \\
\hline Manuscript ID: & TPHM-08-Sep-0300.R1 \\
\hline Journal Selection: & Philosophical Magazine \\
\hline $\begin{array}{r}\text { Date Submitted by the } \\
\text { Author: }\end{array}$ & 06-Nov-2008 \\
\hline Complete List of Authors: & $\begin{array}{l}\text { Danielewski, Marek; AGH, University of Science and Technology, } \\
\text { Physical Chemistry of Solids } \\
\text { Wierzba, Bartek; AGH, University of Science and Technology, } \\
\text { Physical Chemistry of Solids }\end{array}$ \\
\hline Keywords: & constitutive equations, deformation, diffusion \\
\hline Keywords (user supplied): & volume continuity equation, volume density, interdiffusion \\
\hline
\end{tabular}

\section{今scholaroNE \\ Manuscript Central}




\section{Diffusion, Drift and their interrelation through Volume Density.}

\section{Marek Danielewski ${ }^{\mathrm{a}, 1}$ and Bartek Wierzba ${ }^{\mathrm{b}}$}

Interdisciplinary Centre for Materials Modeling, Faculty of Materials Science and Ceramics AGH University of Science and Technology, Al. Mickiewicza 30, 30-059 Cracow, Poland

adaniel@agh.edu.pl, bbwierzba@agh.edu.pl

Abstract. The evolution of the understanding of the mass transport phenomena in solids and liquids allows for the unification of phenomenological models. We consider the central Darken problem of the choice of the coordinate axes for diffusion. Namely, the definition of this mode of motion and the method how diffusion displacement is defined and measured. In our analysis we extensively use the Euler's and Liouville, theorems. We derive the formula of volume density conservation, i.e., the volume continuity equation. This fundamental formula defines the volume-fixed frame of reference in the multicomponent, solid, gas and liquid solutions. The volume fixed frame of reference is self-consistent with the foundations of linear irreversible thermodynamics except recognizing the need to add volume density to the usual list of extensive physical properties undergoing transport in every continuum. Proposed modifications are selfconsistent with the literature dating back to Onsager, the experiments of Kirkendall, their interpretation by Darken and recent generalized formulations. It will be shown that the method can be used in mechano-chemistry and electromechano-chemistry.

Keywords: volume continuity equation; volume density; interdiffusion; mechano-chemistry

\section{INTRODUCTION}

Studies of diffusion in liquids and gases were at the center of interest of scientists in the second half of the nineteenth century. In the twentieth century, the diffusion in solids was a driving force for the chemistry of solids. The Kirkendall experiments and Darken method resulted in different theoretical description of the transport phenomena in solids, Crystals have greater number of control parameters when compared with liquids. These are crystal structure, geometry of crystallites, grain boundaries, defects, strain and stress, etc. So far, the treatments that unify the methods used to desribe the diffusion in solids liquids and gases are scarce.

Recently, noting the conflicts between tracer- and mass-velocity experiments in fluids Brenner has suggested that the fluid's volume velocity (i.e., the convection or drift velocity) is the proper frame of reference for diffusion [1,2]. The experimental data on thermal diffusion in binary liquid mixtures [3,4] support the applicability of the proposed revisions. It was shown that nonequilibrium thermodynamics can be formulated without contradictions with Brenner proposal [5]. According to Öttinger [6]: "Something is missing" in the commonly used transport equations of irreversible thermodynamics $[7,8]$ and he proposed incorporating fluctuations in GENERIC theory [6]. Summing up the above arguments it is clear that in gases, fluids and solids in which diffusion occurs the component's velocity, $v_{i}$, must be divided into the two parts $i$ ) the unique diffusion velocity, $v_{i}^{d}$, that depends on the mechano-chemical potential gradient (in general on the electromechano-chemical potential gradient) and is independent of the choice of the reference frame and ii) the drift velocity, $v^{\text {drift }}$, that is common for all components and depends on the choice of the external reference frame and mechanism of the process. When the stress field is considered and the
Deleted: reduce the gap between these continua and

Deleted: Basing

Deleted: on

Deleted: agrange

Deleted: w

Deleted: $\mathrm{d}$

Deleted: and the gap

Deleted: between

Deleted: and liquids was formed

Deleted: reduce the gap and go beyond

Deleted:

Deleted: electro-

Deleted: only 
partial molar volumes of components differ, the quantitative definition of the drift velocity (material velocity) is an unsolved problem $[1,2]$.

All attempts to combine diffusion and stress based on Euler's view that was formulated $\sim 250$ years ago [9] and the velocity of the local mass centre, $v^{m}$, is generally accepted as an internal frame of reference for the stress field $[10,11,12]$. Formulated by the Euler expression $\rho v^{m}$ in the momentum flux originates from the assumption that Newton's laws of motion for a solid body are also valid in a case of material domain of known mass density $\rho$ moving within a continuum. Euler was obviously unaware of the diffusion and hidden constitutive assumption implicit in the relation $\rho v^{m}$. Since then, this relation was questioned only in a very few circumstances $[13,14]$. On the other hand, the majority of interdiffusion studies are based on the fundamental Darken concept of the lattice-fixed coordinate axes for diffusion [15,16]. In 1948, Darken considered the stress free interdiffusion problem in a binary alloy. He postulated that the volume-fixed reference frame defines the coordinate axes for diffusion and proposed formulae in the case when the total molar concentration of the mixture is constant. Onishi and Shimozaki have found the relation between the diffusion fluxes defined in the volume and concentration-fixed frames of reference [11,17]. Unfortunately, their relations are valid for binary alloys and do not allow the consideration of the stress field.

In earlier papers concerned with the mathematical description of interdiffusion under a stress field we were not aware of the conflict between the volume and the centre of mass reference frames. As a result, the introduction of the partial Cauchy stress tensor [18] was unsuccessful in practical applications due to the unsolved conflict between different coordinate axes for the diffusion and stress. Following Darken, Onishi, Brenner and Öttinger's concepts that the volume velocity defines the local material velocity at nonequilibrium we derived recently the volume continuity equation, i.e., the law of the volume density conservation [19]. This formula allows fixing the unique frame of reference for all diffusion fluxes.

The commonly used definitions of the local overall velocities ignore the convection term due to diffusion and are defined using the component's velocity, $v_{i}$. Obviously $v_{i}$ depends on the choice of reference frame [11]. The mass velocity (i.e., the local mass centre velocity $v^{m}$ ), the molar velocity $v^{M}$, the volume velocity $v^{V}$, and the solvent velocity (i.e., the Hittorf reference frame [20], $\left.J_{i}^{H}=c_{i} v_{i}^{H}=c_{i}\left(v_{i}-v_{r}\right)\right)$ are defined by:

$$
\begin{aligned}
& \rho v^{m}:=\sum_{i=1}^{r} \rho_{i} v_{i} \text { and } v^{m}=\sum_{i=1}^{r} \frac{M_{i}}{M} N_{i} v_{i}, \text { where } \sum_{i=1}^{r} \frac{M_{i} N_{i}}{M}=1, \\
& c v^{M}:=\sum_{i=1}^{r} c_{i} v_{i} \text { and } v^{M}=\sum_{i=1}^{r} N_{i} v_{i}, \text { where } \sum_{i=1}^{r} N_{i}=1, \\
& c \Omega v^{V}:=\sum_{i=1}^{r} \Omega_{i} c_{i} v_{i} \quad \text { and } \quad v^{V}=\sum_{i=1}^{r} N_{i} \frac{\Omega_{i}}{\Omega} v_{i}, \text { where } \sum_{i=1}^{r} \frac{\Omega_{i} N_{i}}{\Omega}=1, \\
& c v^{H}:=\sum_{i=1}^{r} c_{i}\left(v_{i}-v_{r}\right) \quad \text { and } \quad v^{H}=\sum_{i=1}^{r} N_{i} v_{i}-v_{r}, \quad \text { where } \sum_{i=1}^{r} N_{i}=1,
\end{aligned}
$$

where $c_{i}=c_{i}(t, x)_{2} c=c(t, x)=\sum_{i=1}^{r} c_{i}$ and $N_{i}=N_{i}(t, x)=c_{i} / c$ denote the molar concentration of the components, the molar mixture concentration and the molar ratios in the mixture, respectively. $\Omega=\Omega(t, x)$ is the mixture molar volume, $\Omega c$ and $\Omega_{i} c_{i}$ denote the total and partial volume densities.

An expansion of Eqs. (1) - (3) by postulating that convection in solids can be generated by diffusion is the central conclusion that follows from both the Darken method and the experimentally

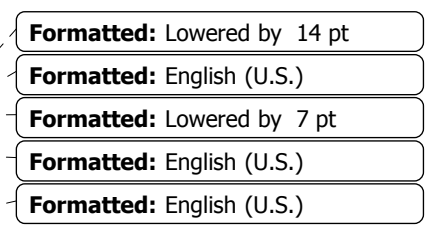
Formatted: English (U.S.) 
proved generation of nonuniform velocity field within the diffusion zone $[15,16]$. The convection velocity was originally termed the drift velocity [15]. In order to avoid conflicts, it will be denoted here as the Darken velocity $v^{D}$. The Darken method assumes 1) the constant and equal component partial molar volumes and 2) the negligible plastic and elastic deformations. Based on Kirkendall's experimental findings [21], Darken concluded that diffusional fluxes are not balanced locally [15]:

$$
\sum_{i=1}^{r} c_{i} v_{i}^{d} \neq 0 \text { and } \operatorname{div} \sum_{i=1}^{r} c_{i} v_{i}^{d} \neq 0
$$

where $v_{i}^{d}$ is the 'unique' $i$-th component diffusion velocity (does not depend on the transport model but requires the proper selection of the constitutive diffusion flux formula).

The Darken velocity, $v^{D}$, in the simplest case of the purely diffusional transport mode equals:

$$
c v^{D}:=-\sum_{i=1}^{r} c_{i} v_{i}^{d} \quad \text { and } \quad v^{D}=-\sum_{i=1}^{r} N_{i} v_{i}^{d} \text { where } c=\text { const. }
$$

Upon taking into account Eq. (6), the molar velocity $v^{M}$, Eq. (2), can be written in the form of the preceding formulae, e.g., $c v^{M}:=\sum_{i=1}^{r} c_{i} v_{i}=\sum_{i=1}^{r} c_{i}\left(v^{t r}+v^{D}+v_{i}^{d}\right)$, where $v^{t r}$ is the translation velocity in the observer reference frame and may depend on time only. In still other words, the Darken method is strictly limited to the processes where $v_{i}(t, x)=v^{t r}(t)+v^{D}(t, x)+v_{i}^{d}(t, x)$ and when the total molar concentration of the mixture is constant, $c=$ const. This method can be generalized to avoid above limitations. We will consider the nonideal, compressible solid solutions $(c \neq$ const. $)$ and merge the following fundamental results:

1) The concept of mobility, the uniqueness of the diffusion velocities and the Nernst-Planck flux formula $[22,23]$

2) Common occurrence of defects in solids (Frenkel and others) [24,25],

3) The nonstoichiometry as a principle, not an exception (Schottky and Wagner [26,27]) and

4) The lattice sites are not conserved in metals (Kirkendall and Darken [15,21]) as well as in ionic compounds [28].

In this work, we advance the already presented pattern [19]. Special emphasis is given to the rigorous derivation of the different expressions for the local overall diffusion velocities. In the following section, we present the method of dividing the component's velocity into the unique diffusion velocity (does not depend on the choice of the reference frame) and a net drift velocity ${ }^{2}$ (depends on the choice of the external reference frame and on the mechanism of the process). The | examination of the volume fixed axis for diffusion will show that only the volume velocity, Eq. (34), can serve as an internal reference frame for all internal processes (the mass diffusion processes, heat transport, deformation etc.) and that it is an inertial frame of reference. Moreover, using the Euler and Lagrange theorems we present: 1) the rigorous derivation of the volume continuity equation, 2) the consistency of the Newton laws with thermodynamics in the volume-fixed reference frame, 3 ) the equivalence of the presented and Darken's methods when the Darken restriction are introduced.

2. The Volume Continuity, Conservation of Mass, Momentum and Energy. In this section, we consider the first Darken problem of choice of the coordinate axes for diffusion. If the motion of the element of multicomponent alloy is to be analyzed, then the first step is to define this motion, i.e., to select the method as to how this displacement is defined and measured. We will consider a motion of a single phase $r$-component mixture, i.e., alloy or solid solution. We define the velocity field of the $i$-th component, $v_{i}:[0, \infty) \times \mathrm{R}^{3} \oplus \mathrm{R}^{3}$, and its molar and mass densities,

\footnotetext{
${ }^{2}$ In what follows it is understood, that the volume velocity is identical to the material velocity, lattice sites velocity, the convection velocity and Kirkendall velocity. The volume reference frame is the unique reference frame identical with the material velocity and defines the coordinate axes for diffusion.
}

Deleted: (34)

Deleted: (35) 
$c_{i}, \rho_{i}:[0, \infty) \times \mathrm{R}^{3} \rightarrow \mathrm{R}$. The notation $X \oplus Y$ means that the domain of a function is a subset (part) of $X$. The theory must combine the following things:

1. The local acceleration due to an external force field(s) depends on the mixture inertial mass, not on the diffusion processes.

2. The local centre of mass position cannot be affected by diffusion (mass diffusion, heat transport, internal friction etc.).

3. The volume velocity is an internal frame of reference for diffusion $[15,16]$, deformation, viscosity, heat transport, etc. [1]. The total, drift and diffusion velocities of components are related by: $v_{i}:=v^{\text {drift }}+v_{i}^{d}$.

4. The unbalanced diffusion fluxes affect the local material velocity $[15,16]$.

The Liouville transport theorem is a key mathematical tool used in this work to obtain the volume continuity equation and other conservation laws. It generalizes the Gauss-Ostrogradzki theorem and allows compressing the mathematics. Let $\Sigma(t)$ denote any subregion of the mixture for any time $t \geq 0$.

THEOREM. If $v_{i}:[0, \infty) \times \mathrm{R}^{3} \rightarrow \mathrm{R}^{3}$ and $\rho_{i}:[0, \infty) \times \mathrm{R}^{3} \rightarrow \mathrm{R}^{3}$ are a sufficiently smooth functions defined on the domain of $v_{i}$, then

$$
\frac{\mathrm{d}}{\mathrm{d} t} \int_{\Sigma(t)} \rho_{i} v_{i} \mathrm{~d} x=\int_{\Sigma(t)}\left[v_{i}\left(\frac{\partial \rho_{i}}{\partial t}+\operatorname{div}\left(\rho_{i} v_{i}\right)\right)+\rho_{i}\left(\frac{\partial v_{i}}{\partial t}+v_{i} \cdot \operatorname{grad} v_{i}\right)\right] \mathrm{d} x .
$$

The proof of the above theorem can be found elsewhere [29].

2.1. Extensive and intensive variables. In what follows, we do neglect the dimensions of the body and surface energy, e.g., interfaces, grain boundaries, etc. We consider the mass density, $\rho_{i}=\rho_{i}(t, x)$ of every mixture component. The mass density, $\rho=\rho(t, x)$ and the molar mass, $M=M(t, x)$, of the mixture are given by:

$$
\begin{aligned}
& \rho=\sum_{i=1}^{r} \rho_{i} \\
& c=\frac{1}{\Omega}=\sum_{i=1}^{r} c_{i}=\sum_{i=1}^{r} \frac{\rho_{i}}{M_{i}}=\frac{\rho}{M}
\end{aligned}
$$

where $M_{i}$ denotes the constant molar mass of the $i$-th component. By definition, Eq. (9), the mixture molar volume density equals one, $\Omega c \equiv 1$.

The volume occupied by the mixture is an extensive variable and is not conserved [30]. If we write:

$\Omega=\Omega\left(N_{1}, \ldots, N_{r} ; T, p\right)$

as the equation of state of the system giving the molar volume in terms of independent variables: $N_{1}, \ldots, N_{r}$ and $T, p$, we have then for an arbitrary volume $\Omega^{*}$ and number of moles $n_{1}, \ldots, n_{r}$ :

$$
\Omega^{*}\left(k n_{1}, \ldots, k n_{r} ; T, p\right)=k \Omega^{*}\left(n_{1}, \ldots, n_{r} ; T, p\right)
$$

which express the fact that the system at a temperature $T$, pressure $p$, and containing $k n_{1}, \ldots, \bar{k} n_{r}$ moles of components occupies a volume $k \Omega^{*}$. $\Omega^{*}$ and $\Omega$ are homogeneous functions of the first degree with respect to composition and Euler's theorem can be applied, This theorem states that the function $f\left(x_{1}, \ldots, x_{r}, \ldots\right)$ is called homogeneous of the $m$-th degree in the variables $x_{1}, \ldots, x_{r}$ if the identity: $f\left(k x_{1}, \ldots, k x_{r} ; \ldots\right) \equiv k^{m} f\left(x_{1}, \ldots, x_{r} ; \ldots\right)$ holds [30]. If we differentiate this definition with respect to $k$ the next identity follows:

\begin{tabular}{l} 
Deleted: 15 \\
Deleted: 15 \\
\hline
\end{tabular}

Deleted: , the molar concentration, $c_{i}=c_{i}(t, x)$

Deleted: and the molar ratio, $N_{i}=N_{i}(t, x)$

Deleted:

Deleted: the molar concentration, $c=c(t, x)$, the molar volume, $\Omega=\Omega(t, x)$,

Deleted: $N_{i}=c_{i} / c$, (10)ף

Formatted: English (U.S.)

Formatted: English (U.S.), Lowered by 3 pt

Formatted: English (U.S.)

Deleted: 10

Deleted: 11

Deleted: 11

Deleted: 12

Deleted: ${ }^{3}$ 


$$
\begin{aligned}
& \sum_{i=1}^{r} x_{i} \frac{\partial f\left(k x_{1}, \ldots, k x_{r} ; \ldots\right)}{\partial k x_{i}} \equiv m k^{m-1} f\left(x_{1}, \ldots, x_{r} ; \ldots\right) \\
& \sum_{i=1}^{r} x_{i} \frac{\partial f\left(x_{1}, \ldots, x_{r} ; \ldots\right)}{\partial x_{i}} \equiv m f\left(x_{1}, \ldots, x_{r} ; \ldots\right) \quad \text { when } \quad k=1 .
\end{aligned}
$$

Eq. (13) is called Euler's theorem. The theory of partial differential equations states that conversely any function $f\left(x_{1}, \ldots, x_{r}, \ldots\right)$ which satisfies Eq. (13) is homogeneous of the $m$-th degree in $x_{1}, \ldots, x_{r}$ [31]. We are concerned with homogeneous functions of the first degree, $m=1$. In such a case:

$$
f\left(k x_{1}, \ldots, k x_{r} ; \ldots\right) \equiv k f\left(x_{1}, \ldots, x_{r} ; \ldots\right)
$$

and Eq. (13) becomes:

$$
\sum_{i=1}^{r} x_{i} \frac{\partial f\left(x_{1}, \ldots, x_{r} ; \ldots\right)}{\partial x_{i}} \equiv f\left(x_{1}, \ldots, x_{r} ; \ldots\right)
$$

Comparing Eqs. (10), (11) and (14) we see that $\Omega$ and $\Omega^{*}$ are homogeneous functions of the first degree in the independent variables $N_{1}, \ldots, N_{r}$. Consequently from Eq. (15) the general relation between the molar volume of the mixture and partial molar volumes follows:

$$
\sum_{i=1}^{r} N_{i} \frac{\partial \Omega\left(N_{1}, \ldots, N_{r} ; T, p\right)}{\partial N_{i}}=\sum_{i=1}^{r} \Omega_{i} N_{i} \equiv \Omega\left(N_{1}, \ldots, N_{r} ; T, p\right) .
$$

where $\Omega_{i}$ is the partial molar volume.

From (9) and (16) the following identities hold:

$$
\sum_{i=1}^{r} \frac{\Omega_{i}}{\Omega} N_{i} \equiv \sum_{i=1}^{r} \frac{\Omega_{i} c_{i}}{\Omega c} \equiv \sum_{i=1}^{r} \Omega_{i} c_{i} \equiv 1
$$

where $\Omega_{i} c_{i}$ and $\Omega c$ denote the partial and total molar volume densities.

The relation above is valid for an arbitrary mixture and allows the conclusion that the total volume

density of the arbitrary mixture is conserved and equals unity ${ }^{4}$, Eq. (17).

2.2. The fluxes and velocities. The fluxes and velocities of the mass, $v^{m}$, molar, $v^{M}$ and volume [11], $v^{V}$, can be defined by the drift velocity and the unique diffusion velocity (may depend only on the choice of the constitutive equations for diffusion):

$$
\begin{aligned}
& \rho v^{m}=\sum_{i=1}^{r}\left(\rho_{i} v^{d r i f t}+\rho_{i} v_{i}^{d}\right) \text { and } v^{m}:=v^{d r i f t}+\sum_{i=1}^{r} \frac{M_{i}}{M} N_{i} v_{i}^{d}, \\
& c v^{M}=\sum_{i=1}^{r}\left(c_{i} v^{d r i f t}+c_{i} v_{i}^{d}\right) \text { and } v^{M}:=v^{d r i f t}+\sum_{i=1}^{r} N_{i} v_{i}^{d}, \\
& c \Omega v^{V}=\sum_{i=1}^{r}\left(c_{i} \Omega_{i} v^{d r i f t}+c_{i} \Omega_{i} v_{i}^{d}\right) \text { and } v^{V}:=v^{d r i f t}+\sum_{i=1}^{r} \frac{\Omega_{i}}{\Omega} N_{i} v_{i}^{d},
\end{aligned}
$$

\begin{tabular}{|c|}
\hline Deleted: 12 \\
\hline Deleted: 13 \\
\hline Deleted: 13 \\
\hline Deleted: 14 \\
\hline Deleted: (13) \\
\hline Deleted: (14) \\
\hline Deleted: (13) \\
\hline Deleted: (14) \\
\hline Deleted: 14 \\
\hline Deleted: 15 \\
\hline Deleted: (13) \\
\hline Deleted: (14) \\
\hline Deleted: 15 \\
\hline Deleted: 16 \\
\hline Deleted: (10) \\
\hline Deleted: (11) \\
\hline Deleted: (11) \\
\hline Deleted: (12) \\
\hline Deleted: (14) \\
\hline Deleted: (15) \\
\hline Deleted: (15) \\
\hline Deleted: (16) \\
\hline Deleted: 16 \\
\hline Deleted: 17 \\
\hline Deleted: (16) \\
\hline Deleted: (17) \\
\hline Deleted: 17 \\
\hline Deleted: 18 \\
\hline Deleted: (17) \\
\hline Deleted: (18) \\
\hline Deleted: 18 \\
\hline Deleted: 19 \\
\hline Deleted: 19 \\
\hline Deleted: 20 \\
\hline Deleted: 20 \\
\hline Deleted: 21 \\
\hline
\end{tabular}

where $\Omega c$ and $\Omega_{i} c_{i}$ denote the total and partial volume densities.

The total diffusion velocities differ. This is apparent by writing Eqs. (18) - (20) in the form:

$$
\begin{aligned}
& v^{m}:=v^{d r i f t}+v_{m}^{d} \text { where } v_{m}^{d}:=\sum_{i=1}^{r} \frac{M_{i}}{M} N_{i} v_{i}^{d}=\sum_{i=1}^{r} \frac{M_{i}}{M} \Omega c_{i} v_{i}^{d}, \\
& v^{M}:=v^{d r i f t}+v_{M}^{d} \text { where } v_{M}^{d}=\sum_{i=1}^{r} N_{i} v_{i}^{d}=\sum_{i=1}^{r} \Omega c_{i} v_{i}^{d},
\end{aligned}
$$

Deleted: 21

\begin{tabular}{|l|} 
Deleted: (18) \\
Deleted: (19) \\
Deleted: (20) \\
Deleted: $(21)$ \\
Deleted: 21 \\
Deleted: 22 \\
Deleted: 22 \\
Deleted: 23
\end{tabular}

${ }^{4}$ Unless we consider/allow the formation of cracks and/or voids. 
2.3. Diffusion. The diffusion velocity, $v_{i}^{d} \equiv J_{i}^{d} / c_{i}$, of every component can be expressed by an appropriate formula, e.g., by the Nernst-Planck equation [22,23], Fick's first law [32], the Onsager flux [33] or the electro-mechano-chemical flux:

$$
\begin{aligned}
& v_{i}^{d}=-B_{i} \operatorname{grad}\left(\mu_{i}^{c h}+\mu_{i}^{e l}\right) \quad \text { where } \mu_{i}^{e l}=z_{i} F \varphi, \\
& v_{i}^{d}=-D_{i} \operatorname{grad} \ln c_{i}, \\
& v_{i}^{d}=\sum_{j=1}^{k} \frac{L_{i j}}{c_{i}} X_{j}, \\
& v_{i}^{d}=-B_{i} \operatorname{grad}\left(\mu_{i}^{c h}+\Omega_{i} p+z_{i} F \varphi\right)=-B_{i} \operatorname{grad}\left(\mu_{i}^{c h}+\mu_{i}^{m}+\mu_{i}^{e l}\right) \text { where } \sum_{i=1}^{r} c_{i} \mu_{i}^{m}=p,
\end{aligned}
$$

where $B_{i}, D_{i}, z_{i}$ denote the mobility, diffusivity and valence of the $i$-th component, respectively. $F$ and $\varphi$ are the Faraday constant and electric potential.

The above equations comply with the definition of diffusion as a process that depends on the rate of energy dissipation. This definition centers on the basic difference between Newton mechanics $\left(a_{i}=\dot{v}_{i} \sim F_{i}\right)$ vs. diffusion $\left(v_{i}^{d} \sim F_{i}\right)$. In what follows, we consider the mechanochemical flux formula and the case when the drift velocity is a result of deformation, $v^{\sigma}$, of the Darken drift, $v^{D}$ and translation, $v^{t r}$, i.e., the diffusion flux in the form $v_{i}^{d}=-B_{i} \operatorname{grad}\left(\mu_{i}^{c h}+\Omega_{i} p\right)=-B_{i} \operatorname{grad}\left(\mu_{i}^{c h}+\mu_{i}^{m}\right)$.

$$
v^{d r i f t}=v^{\sigma}+v^{D}+v^{t r},
$$

where the Darken drift is the velocity generated by unbalanced diffusion fluxes $[15,16]$.

2.4. Volume Continuity Equation and Darken Drift. In irreversible thermodynamics the partial molar volumes are intensive parameters and are not conserved. They are transported by the velocity field of every mixture component. Contrary, the molar volume density of the mixture, $c \Omega$, equals unity, Eq. (9), and is conserved during an arbitrary transport process in the continuum. From the Euler identities, Eq. (17), it follows that:

$$
\frac{\mathrm{d}}{\mathrm{d} t} \int_{\Sigma(t)} \sum_{i=1}^{r} c_{i} \Omega_{i} \mathrm{~d} x=\frac{\mathrm{d}}{\mathrm{d} t} \int_{\Sigma(t)} c \Omega \mathrm{d} x=0 .
$$

Equation (29) states that the volume density of the mixture does not depend on time, i.e., the total volume density is conserved ${ }^{5}$. It was used by Darken and Onishi but is inadequate in our case. The time evolution of the volume velocity is necessary in order to separate the internal processes from the momentum of the mixture itself and to define the internal reference frame [1]. From the Liouville transport theorem and the Euler identities, Eqs. (7) and (17), it follows that:

$$
\frac{\mathrm{d}}{\mathrm{d} t} \int_{\Sigma(t)} \sum_{i=1}^{r} c_{i} \Omega_{i} \mathrm{~d} x=\int_{\Sigma(t)}\left(\frac{\partial}{\partial t} \sum_{i=1}^{r} c_{i} \Omega_{i}+\operatorname{div} \sum_{i=1}^{r} c_{i} \Omega_{i} v_{i}\right) \mathrm{d} x=0 .
$$

Combining Eqs. (29)-(30) and since the subregion $\Sigma(t)$ was chosen arbitrarily, then:

\footnotetext{
${ }^{5}$ Unless voids and/or cracks are formed.
}

\begin{tabular}{|l|}
\hline Deleted: 24 \\
\hline Deleted: 25 \\
\hline Deleted: 25 \\
\hline Deleted: 26 \\
\hline Deleted: 26 \\
\hline Deleted: 27 \\
\hline Deleted: 27 \\
\hline Deleted: 28 \\
\hline
\end{tabular}

Deleted: (17)
Deleted: (18)
Deleted: 29
Deleted: 30
Deleted: (29)
Deleted: (30)

\begin{tabular}{|l|}
\hline Deleted: (17) \\
Deleted: (18) \\
Deleted: 30 \\
Deleted: 31 \\
Deleted: (29) \\
Deleted: (30) \\
Deleted: (30) \\
Deleted: (31)
\end{tabular}




$$
\operatorname{div}\left(\sum_{i=1}^{r} c_{i} \Omega_{i} v_{i}\right)=0
$$

The above relation is the volume continuity equation. It permits the analysis of an arbitrary transport process in the multicomponent mixture.

By adding the fluxes of the all mixture components ${ }^{6}$ and from relations (23) and (28) one gets:

$$
v^{V}=c \Omega v^{V}=\sum_{i=1}^{r} c_{i} \Omega_{i}\left(v^{D}+v^{\sigma}+v^{t r}+v_{i}^{d}\right)=v^{D}+v^{\sigma}+v^{t r}+\sum_{i=1}^{r} c_{i} \Omega_{i} v_{i}^{d}=v^{d r i f t}+v_{V}^{d} .
$$

The molar flux of the $i$-th component equals:

$$
J_{i}^{M}=c_{i} v_{i}=c_{i} v^{D}+c_{i} v^{\sigma}+c_{i} v^{t r}+c_{i} v_{i}^{d}=c_{i} v^{d r i f t}+c_{i} v_{i}^{d}=c_{i} v^{d r i f t}+J_{i}^{d} .
$$

where $v^{\text {drift }}=v^{D}+v^{\sigma}+v^{t r}$ and $J_{i}^{d}$ are the drift velocity and the diffusion flux of the $i$-th | component. Multiplying Eq. (33) by the $i$-th component molar mass or partial molar volume one gets the mass or volume flux of the $i$-th component. The drift (e.g., the Darken velocity) is a variable that can be calculated from Eqs. (31) and (32).

Example. In the case of an ideal solid solution ( $c=$ const.), Kirkendall experimentally [21], Darken theoretically [15] and one of the authors in multicomponent solid mixtures [16] have shown that the local sum of diffusion fluxes has not to be zero as well as $\operatorname{div}\left(\sum_{i=1}^{r} c_{i} v_{i}^{d}\right) \neq 0$, i.e., the law of I conservation of lattice sites does not exist [19]. Thus, in the more general case when $c \neq$ const. $\left(\Omega_{i} \neq\right.$ $\Omega)$, the volume continuity implies that the Darken velocity, $v^{D}$, has to be generated during the diffusion process. Let us consider the pure diffusion process in an incompressible multicomponent mixture: $J_{i}^{d}=c_{i} v_{i}^{d}$, for $i=1,2, \ldots, r$ and $v^{d r i f t}=v^{D}$. Thus, from Eqs. (28) and (31) it follows that:

$$
\operatorname{div}\left(\sum_{i=1}^{r} c_{i} \Omega_{i} v^{D}+\sum_{i=1}^{r} c_{i} \Omega_{i} v_{i}^{d}\right)=\operatorname{div}\left(v^{D}+\sum_{i=1}^{r} c_{i} \Omega_{i} v_{i}^{d}\right)=0
$$

i.e., the Darken drift velocity is generated by diffusion. In section 3 we show that when Darken simplified conditions are valid Eq. (34) results in the Darken expression.

2.5. Conservation of Mass. The molar mass of the mixture component, $m_{i}(t)$, contained in $\Sigma(t)$ at the moment $t$ is:

$$
m_{i}(t)=\int_{\Sigma(t)} c_{i} \mathrm{~d} x
$$

The principle of conservation of mass states that the mass in $\Sigma(t)$ is conserved ${ }^{7}$. Thus,

$$
\frac{\mathrm{d}}{\mathrm{d} t} \int_{\Sigma(t)} c_{i} \mathrm{~d} x=0
$$

\begin{tabular}{|c|}
\hline Deleted: (23) \\
\hline Deleted: (24) \\
\hline Deleted: (28) \\
\hline Deleted: (29) \\
\hline Deleted: 32 \\
\hline Deleted: 33 \\
\hline Deleted: 33 \\
\hline Deleted: 34 \\
\hline Deleted: (33) \\
\hline Deleted: (34) \\
\hline Deleted: $\underline{(31)}$ \\
\hline Formatted: Font: Bold, Underline \\
\hline $\begin{array}{l}\text { Formatted: Font: Bold, Underline, } \\
\text { Check spelling and grammar }\end{array}$ \\
\hline Formatted: Font: Bold, Underline \\
\hline Deleted: $\underline{(32)}$ \\
\hline Deleted: (32) \\
\hline Deleted: $\underline{(33)}$ \\
\hline Formatted: Font: Bold, Underline \\
\hline $\begin{array}{l}\text { Formatted: Font: Bold, Underline, } \\
\text { Check spelling and grammar }\end{array}$ \\
\hline Formatted: Font: Bold, Underline \\
\hline Formatted: Font: Bold, Underline \\
\hline $\begin{array}{l}\text { Formatted: Font: Bold, Underline, } \\
\text { Check spelling and grammar }\end{array}$ \\
\hline Formatted: Font: Bold, Underline \\
\hline Formatted: Font: Bold, Underline \\
\hline $\begin{array}{l}\text { Formatted: Font: Bold, Underline, } \\
\text { Check spelling and grammar }\end{array}$ \\
\hline Formatted: Font: Bold, Underline \\
\hline Deleted: (28) \\
\hline Deleted: (29) \\
\hline Deleted: (31) \\
\hline Deleted: (32) \\
\hline Deleted: 34 \\
\hline Deleted: 35 \\
\hline Deleted: (34) \\
\hline Deleted: (35) \\
\hline Deleted: 35 \\
\hline Deleted: 36 \\
\hline Deleted: 36 \\
\hline Deleted: 37 \\
\hline Deleted: (36) \\
\hline Deleted: (37) \\
\hline
\end{tabular}

By the Liouville theorem $\left(v_{i} \equiv 1\right)$ from $(7)$ and $\underline{(36)}$ we get:

\footnotetext{
${ }^{6}$ In this work, we do consider the deformation, translation and Darken velocities. Their sum results in the drift velocity in the mixture. Incorporating velocity due to thermal expansion, etc. does not affect the formalism.

${ }^{7}$ To simplify the relations, in this work we do not consider the chemical and/or nuclear reactions in the mixture, i.e., we
} do neglect the local sources and sinks of mass. 


$$
\frac{\mathrm{d}}{\mathrm{d} t} \int_{\Sigma(t)} c_{i} \mathrm{~d} x=\int_{\Sigma(t)}\left[\frac{\partial c_{i}}{\partial t}+\operatorname{div}\left(c_{i} v_{i}\right)\right] \mathrm{d} x=0,
$$

Since the subregion $\Sigma(t)$ was chosen arbitrarily, then

$$
\frac{\partial c_{i}}{\partial t}+\operatorname{div}\left(c_{i} v_{i}\right)=0,
$$

\section{Deleted: 38}

Deleted: 39

Upon summing up for all components the partial continuity equations, Eqs. (38), and introducing the definition $(33)$ one can get the global conservation law:

$$
\frac{\partial c}{\partial t}+\operatorname{div}\left(c v^{M}\right)=0,
$$

Equations (38) and (39) are known as the partial and global continuity equations.

2.6. Balance of Momentum. The momentum of a multicomponent mixture in an evolving subregion $\Sigma(t)$ is:

$$
[\text { momentum in } \Sigma(t)]=\int_{\Sigma(t)} \rho v^{m} \mathrm{~d} x .
$$

By Newton's law the rate of momentum change equals the total force acting on the mass in $\Sigma(t)$ :

$$
\mathrm{F}_{\text {total }}=\frac{\mathrm{d}}{\mathrm{d} t} \int_{\Sigma(t)} \rho v^{m} \mathrm{~d} x
$$

We assume that the following forces act on the mass in $\Sigma(t)^{8}$ :

1. The force of elastic stress, $\boldsymbol{F}_{\sigma}$, acting on the surface $\partial \Sigma(t)$

$$
\mathrm{F}_{\sigma}=\int_{\partial \Sigma(t)} \sigma^{e} \mathrm{~d} x=\int_{\Sigma(t)} \operatorname{Div} \sigma^{e} \mathrm{~d} x,
$$

where $\sigma^{e}:[0, \infty) \times \beta^{\beta} \Leftrightarrow \mathrm{L}\left(\beta^{\beta}, \beta^{\beta}\right)$ is the stress tensor and $L\left({ }^{\beta}, \beta^{\beta}\right)$ is the space of linear mappings from $\beta^{\beta}$ to ${ }^{\beta}$ [13]. In Eq. (42) we postulate that the mechanical properties of the mixture, the temperature and its entropy, are represented by average values.

2. The viscosity force acting on the mass in $\Sigma(t)$, is a result of the non-uniform volume velocity field. The area was extensively studied and a vast number of constitutive equations is known [13]. Here it is sufficient to use the basic expression:

$$
\mathrm{F}_{v}=\int_{\Sigma(t)} \operatorname{Div} \sigma^{p} \mathrm{~d} x
$$

3. The net chemical force acting on the mass in $\Sigma(t)$. This part of the stress tensor is called the stress free deformation tensor ${ }^{9}[10]$. In nonideal systems the net chemical force equals:

$$
\mathrm{F}_{\text {chem }}=-\sum_{i=1}^{\mathrm{r}} \int_{\Sigma(t)} c_{i} \operatorname{grad} \mu_{i}^{c h} \mathrm{~d} x,
$$

\section{Deleted: 43}

Deleted: 44

4. The external force, $f^{\text {ext }}$, acting on the mass in the volume $\Sigma(t)$ is given by:

${ }^{8} \mathrm{We}$ do not consider here the electromagnetic field, e.g. the diffusion of charged species (ions).

${ }^{9}$ The stress free deformation tensor equals zero in the case of an ideal mixture. 


$$
\mathrm{F}_{\mathrm{ext}}=\int_{\Sigma(t)} \rho f^{e x t} \mathrm{~d} x=-\int_{\Sigma(t)} \rho \operatorname{grad} V^{e x t} \mathrm{~d} x .
$$

An external force can be, e.g., the gradient of a gravitational potential, $f^{\text {ext }}=-\operatorname{grad} V^{\text {ext }}$.

The total force acting on the mass in $\Sigma(t)$ is the sum of all forces listed above. Consequently:

$$
\mathrm{F}_{\text {total }}=\mathrm{F}_{\sigma}+\mathrm{F}_{v}+\mathrm{F}_{\text {chem }}+\mathrm{F}_{\text {ext }}
$$

Applying the formulae (40) and (42) - (46) results in:

$$
\frac{\mathrm{d}}{\mathrm{d} t} \int_{\Sigma(t)} \rho v^{m} \mathrm{~d} x=\int_{\Sigma(t)} \operatorname{Div} \sigma^{e} \mathrm{~d} x+\int_{\Sigma(t)} \operatorname{Div} \sigma^{p} \mathrm{~d} x-\sum_{i=1}^{\mathrm{r}} \int_{\Sigma(t)} c_{i} \operatorname{grad} \mu_{i}^{c h} \mathrm{~d} x-\int_{\Sigma(t)} \rho \operatorname{grad} V^{e x t} \mathrm{~d} x .
$$

\begin{tabular}{|c|c|}
\hline Deleted: 46 & \\
\hline Deleted: 47 & \\
\hline Deleted: $(40)$ & \\
\hline Deleted: (41) & \\
\hline Formatted & $\ldots[1]$ \\
\hline Deleted: (42) & \\
\hline Deleted: (43) & \\
\hline Deleted: (46) & \\
\hline Formatted & $\ldots[2]$ \\
\hline Deleted: (47) & \\
\hline Formatted & $\ldots[3]$ \\
\hline Formatted & $\ldots[4]$ \\
\hline Deleted: 47 & \\
\hline Deleted: 48 & \\
\hline Formatted & $\ldots[5]$ \\
\hline Deleted: (47) & \\
\hline Formatted & $\ldots[6]$ \\
\hline Deleted: (48) & \\
\hline Deleted: 48 & \\
\hline Deleted: 49 & \\
\hline Formatted & $\ldots[7]$ \\
\hline Deleted: (48) & \\
\hline Formatted & $\ldots[8]$ \\
\hline Deleted: (49) & \\
\hline Formatted & $\ldots[9]$ \\
\hline Deleted: (47) & \\
\hline Formatted & $\ldots[10]$ \\
\hline Deleted: (48) & \\
\hline Deleted: 49 & \\
\hline Deleted: 50 & \\
\hline Deleted: (49) & \\
\hline Deleted: (50) & \\
\hline Deleted: 50 & \\
\hline Deleted: 51 & \\
\hline
\end{tabular}

Using the Liouville theorem and the mass continuity equation the left hand side of Eq. (47) becomes:

$$
\frac{\mathrm{d}}{\mathrm{d} t} \int_{\Sigma(t)} \rho v^{m} \mathrm{~d} x=\int_{\Sigma(t)}\left(v^{m}\left(\frac{\partial \rho}{\partial t}+\operatorname{div}\left(\rho v^{m}\right)\right)+\rho\left(\frac{\partial v^{m}}{\partial t}+v^{m} \cdot \operatorname{Grad} v^{m}\right)\right) \mathrm{d} x=\left.\int_{\Sigma(t)} \rho \frac{\mathrm{D} v^{m}}{\mathrm{D} t}\right|_{v^{m}} \mathrm{~d} x .
$$

where $\left.\frac{\mathrm{D} \square}{\mathrm{D} t}\right|_{v}=\frac{\partial \square}{\partial t}+v \cdot \operatorname{grad} \square$ and $\sqcup$ is any sufficiently smooth function.

Substituting Eq. (48) into Eq. (47) one obtains:

$$
\left.\int_{\Sigma(t)} \rho \frac{\mathrm{D} v^{m}}{\mathrm{D} t}\right|_{\nu^{m}} \mathrm{~d} x=\int_{\Sigma(t)} \operatorname{Div} \sigma^{e} \mathrm{~d} x+\int_{\Sigma(t)} \operatorname{Div} \sigma^{p} \mathrm{~d} x-\sum_{i=1}^{\mathrm{r}} \int_{\Sigma(t)} c_{i} \operatorname{grad} \mu_{i}^{c h} \mathrm{~d} x-\int_{\Sigma(t)} \rho \operatorname{grad} V^{e x t} \mathrm{~d} x
$$

Since the subregion $\Sigma(t)$ was chosen arbitrarily, one can omit integrals and Eq. (49) becomes:

$$
\left.\rho \frac{\mathrm{D} v^{m}}{\mathrm{D} t}\right|_{v^{m}}=\operatorname{Div}\left(\sigma^{e}+\sigma^{p}\right)-\sum_{i=1}^{r} c_{i} \operatorname{grad} \mu_{i}^{c h}-\rho \operatorname{grad} V^{e x t} .
$$

We shall call Equation (51) the equation of motion.

\subsection{Balance of Energy.}

We begin with the derivation of the convenient form of the density of the internal energy formulae.

I To compute the internal energy we shall use the fundamental canonical equation of thermodynamics:

$$
U=U\left(S, \Omega^{*}, m_{1}, m_{2}, \ldots, m_{r}\right)
$$

It is convenient to analyze transport in the unit volume, $\Omega^{*}$, moreover, the volume is considered as an inner reference frame. Thus:

$$
\stackrel{v}{\varepsilon}=\stackrel{v}{\varepsilon}\left(\stackrel{v}{s}, \rho_{1}, \rho_{2}, \ldots, \rho_{r}\right)
$$

where $\varepsilon$ and $v$ denote the internal energy and the entropy that are expressed per unit volume. Consequently, the fundamental canonical equation of thermodynamics becomes:

$$
\stackrel{\varepsilon}{\varepsilon}=\rho \varepsilon=\check{\varepsilon}\left(\rho s, \rho_{1}, \rho_{2}, \ldots, \rho_{r}\right)
$$

$\varepsilon$ and $s$ are an internal energy and entropy per mass unit. The transition from the fundamental canonical form to Eq. (51) implies introduction of the mechanical potential. In such a case, the Gibbs equation becomes:

$$
\mathrm{d}(\rho \varepsilon)=T \mathrm{~d}(\rho s)+\sum_{i=1}^{r} \mu_{i}^{*} M_{i}^{-1} \mathrm{~d} \rho_{i}=T \mathrm{~d}(\rho s)+\sum_{i=1}^{r}\left(\mu_{i}^{c h}+\mu_{i}^{m}\right) \mathrm{dc}_{i}
$$

\begin{tabular}{|l|}
\hline Deleted: 51 \\
Deleted: 52 \\
Deleted: $(51)$ \\
Deleted: $(52)$ \\
Deleted: 52 \\
Deleted: 53
\end{tabular}


$\mu_{i}^{c h}, \mu_{i}^{m}$ and $\mu_{i}^{*}$ are the chemical, mechanical and mechano-chemical potentials of components. The mechanical potential due to the deformation can be given by any proper formula, e.g., by Eq. (27). The integral form of the Gibbs equation follows from Eq. (52):

$$
\rho \varepsilon=T s \rho+\sum_{i=1}^{r} \mu_{i}^{*} c_{i}=T s \rho+\sum_{i=1}^{r} \mu_{i}^{c h} c_{i}+\sum_{i=1}^{r} \mu_{i}^{m} c_{i} .
$$

The total energy of the mixture in $\Sigma(t)$ can be written as:

$$
\begin{gathered}
e(t)=e_{k}(t)+e_{I}(t)+e_{P}(t) \\
{\left[\begin{array}{c}
\text { total energy of } \\
\text { mass in } \Sigma(t)
\end{array}\right]=\left[\begin{array}{l}
\text { kinetic } \\
\text { energy }
\end{array}\right]+\left[\begin{array}{l}
\text { internal } \\
\text { energy }
\end{array}\right]+\left[\begin{array}{c}
\text { potential } \\
\text { energy }
\end{array}\right]}
\end{gathered}
$$

The kinetic energy contained in the moving subregion $\Sigma(t)$ with a mass velocity $v^{m}$ is:

$$
e_{k}(t)=\int_{\Sigma(t)} \frac{1}{2} \rho\left(v^{m}\right)^{2} d x .
$$

\begin{tabular}{|l|}
\hline Deleted: 54 \\
\hline Deleted: 55 \\
\hline
\end{tabular}

The potential energy of mass in $\Sigma(t)$ is represented by its potential per the mass unit:

$$
e_{P}=\int_{\Sigma(t)} \rho V^{e x t} \mathrm{~d} x .
$$

The internal energy of mass contained by $\Sigma(t)$ from Eq. (53) is given by:

$e_{\mathrm{I}}=\int_{\Sigma(t)} \rho \varepsilon \mathrm{d} x=\int_{\Sigma(t)}\left(T S \rho+\sum_{i=1}^{r} \mu_{i}^{*} c_{i}\right) \mathrm{d} x=\int_{\Sigma(t)}\left(T S \rho+\sum_{i=1}^{r} \mu_{i}^{c h} c_{i}+\sum_{i=1}^{r} \mu_{i}^{m} c_{i}\right) \mathrm{d} x$

By the First Law of Thermodynamics the total energy of mass contained by $\Sigma(t)$ can be affected by

the heat flow and the work done on it. Thus, from Eqs. (54) (56):

$$
\begin{gathered}
\frac{\mathrm{d}}{\mathrm{dt}} \int_{\Sigma(t)}\left(\frac{1}{2} \rho\left(v^{m}\right)^{2}+T s \rho+\sum_{i=1}^{r} \mu_{i}^{*} c_{i}+V^{e x t} \rho\right) \mathrm{d} x= \\
=\int_{\partial \Sigma(t)} \sigma^{e} \cdot v^{m} \mathrm{~d} a+\int_{\partial \Sigma(t)} \sigma^{p} \cdot v^{m} \mathrm{~d} a-\int_{\Sigma(t)} \operatorname{div} J_{q} \mathrm{~d} x=\int_{\Sigma(t)} \operatorname{div}\left(\sigma^{e} \cdot v^{m}+\sigma^{p} \cdot v^{m}-J_{q}\right) \mathrm{d} x
\end{gathered}
$$

where $J_{q}$ denotes the heat flux, which is given by the proper constitutive formula.

Applying the Liouville theorem Eq. (57) becomes:

$$
\begin{gathered}
\int_{\Sigma(t)}\left(\frac{\partial}{\partial t}\left(\frac{1}{2} \rho\left(v^{m}\right)^{2}+T \rho s+\sum_{i=1}^{r} c_{i} \mu_{i}^{*}+\rho V^{e x t}\right)+\operatorname{div}\left(\frac{1}{2} \rho\left(v^{m}\right)^{2} v^{m}+T s \rho v^{m}+\sum_{i=1}^{r} c_{i} \mu_{i}^{*} v^{m}+\rho V^{e x t} v^{m}\right)\right) \mathrm{d} x= \\
=\int_{\Sigma(t)} \operatorname{div}\left(\sigma^{e} \cdot v^{m}\right) \mathrm{d} x+\int_{\Sigma(t)} \operatorname{div}\left(\sigma^{p} \cdot v^{m}\right) \mathrm{d} x-\int_{\Sigma(t)} \operatorname{div} J_{q} \mathrm{~d} x
\end{gathered}
$$

Since the subregion $\Sigma(t)$ was chosen arbitrarily, the integral in Eq. (58) can be omitted and using the mass continuity equation, it can be written in the condensed form as:

$$
\left.\sum_{i=1}^{r} \rho_{i} \frac{\mathrm{D}}{\mathrm{D} t}\left(\frac{1}{2}\left(v^{m}\right)^{2}+T s+\mu_{i}^{*} M_{i}^{-1}+V^{e x t}\right)\right|_{v^{m}}=\operatorname{div}\left(\sigma^{e} \cdot v^{m}\right)+\operatorname{div}\left(\sigma^{p} \cdot v^{m}\right)-\operatorname{div} J_{q}
$$

The left hand side of the Eq. (59) can be rearranged to:

Deleted: (27)
Deleted: (28)
Deleted: $(52)$
Deleted: $(53)$
Deleted: 53
Deleted: 54


2.8. Separation of mechanical and thermal terms. The separation of the entropy and mechanical energy terms in Eq. (63) is convenient in many applications [13]. Thus, one can write Eq. (63) as:

$$
\begin{aligned}
& \left.\sum_{i=1}^{r} c_{i} \frac{\mathrm{D} \mu_{i}^{*}}{\mathrm{D} t}\right|_{v^{m}}=\sigma^{e}: \operatorname{Grad} v^{m}+v^{m} \sum_{i=1}^{r} c_{i} \operatorname{grad} \mu_{i}^{c h} \\
& \left.\rho \frac{\mathrm{D} T s}{\mathrm{D} t}\right|_{v^{m}}=\sigma^{p}: \operatorname{Grad} v^{m}-\operatorname{div} J_{q}
\end{aligned}
$$

To complete the separation of the mechanical and entropy terms, Eqs. (64) and (65) must be extended to include the dissipation of energy due to the diffusion [13]. From Eqs. (51) and (52), the Gibbs-Duhem relation has the form:

$$
\rho s \mathrm{~d} T=-\sum_{i=1}^{r} c_{i} \mathrm{~d} \mu_{i}^{*}=-\sum_{i=1}^{r} c_{i} \mathrm{~d}\left(\mu_{i}^{c h}+\mu_{i}^{m}\right)
$$

and the energy dissipated due to the diffusion, i.e., the work done by the chemical forces (diffusion forces) equals:

$$
w_{\text {diffusion }}=-\sum_{i=1}^{r} c_{i} v_{i}^{d} \operatorname{grad} \mu_{i}^{*}
$$

This work has to be included into the energy balance, Eqs. (64) and (65), in such a way that it will not change the total energy conservation equation, Eq. (63) [13]. Consequently we get:

$$
\begin{aligned}
& \left.\sum_{i=1}^{r} c_{i} \frac{\mathrm{D} \mu_{i}^{*}}{\mathrm{D} t}\right|_{v^{m}}=\sigma^{e}: \operatorname{Grad} v^{m}+v^{m} \sum_{i=1}^{r} c_{i} \operatorname{grad} \mu_{i}^{c h}+\sum_{i=1}^{r} c_{i} v_{i}^{d} \operatorname{grad} \mu_{i}^{*}, \\
& \left.\rho \frac{\mathrm{D} T s}{\mathrm{D} t}\right|_{v^{m}}=\sigma^{p}: \operatorname{Grad} v^{m}-\operatorname{div} J_{q}-\sum_{i=1}^{r} c_{i} v_{i}^{d} \operatorname{grad} \mu_{i}^{*}
\end{aligned}
$$

The last terms in Eqs. (68) and (69) describe the fact that diffusion does not affect the internal energy of the mixture. Entropy is produced at the expense of mechanical energy of the mixture. One may note that, upon adding Eqs. (68) and (69) we get Eq. (63).

\section{Deleted: 61}

Deleted: (50)

Deleted: (51)

Formatted

Formatted

Deleted: 61

Deleted: 62

Deleted: (55)

Deleted: (56)

Deleted: (62)

Formatted

Deleted: (60)

Formatted

Deleted: (61)

Deleted: (61)

Deleted: 62

Deleted: 63

Deleted: 63

Deleted: 64

Deleted: (62)

Deleted: (63)

Formatted

Deleted: (63)

Formatted

Deleted: (64)

Formatted

Deleted: (63)

Formatted

Deleted: (64)

Deleted: (63)

Formatted

Deleted: (64)

Formatted

Deleted: 64

Deleted: 65

Deleted: 65

Deleted: 66

Deleted: (64)

Deleted: (65)

Deleted: (65)

Deleted: (66)

Formatted

Deleted: (51)

Formatted

Deleted: (52)

Formatted

Deleted: (52)

Formatted

Deleted: (53)

Deleted: 66

Deleted: 67

Deleted: 67

Deleted: 68

Deleted: (64) 


\section{DISCUSSION}

One can show that the presented method is based on the inertial reference frame and reduces to well known relations when simplified conditions are valid.

Invariance of diffusion. The diffusion occurs in a certain medium that may move with a drift velocity, $v^{\text {drift }}$, and the velocity of diffusion is measured with respect to it. When the diffusion flux is expressed by the Nernst-Planck formula then the diffusion velocity equals:

$$
v_{i}^{d}(t, \mathbf{x}):=-B_{i} \operatorname{grad} \mu_{i}(t, \mathbf{x})
$$

The obvious inference is that this speed must be equal to all observers. Moreover, the mass conservation law of every component must always be valid. When the chemical reactions do not occur, it has form of Eq. (38)

$$
\frac{\partial \rho_{i}(t, \mathbf{x})}{\partial t}+\operatorname{div}\left(\rho_{i} v_{i}\right)(t, \mathbf{x})=0
$$

Again, it is evident that this law must be valid to all observers.

$$
\text { z - }
$$

Deleted: 70
Deleted: 71

The reference frame is chosen as a matter of convenience, and generally varies from one observer to another. To relate data from different frames we need a rule, a transformation law, that translates the reading in one frame to another and such a law must be independent of the observer.

The transformation law must be expressed by an equation that has the same form in all frames In other words, the physical laws and constitutive equations must be invariant with respect to the transformation law. The parameterization of absolute space-time by vectors $\mathbf{x}=\left(x^{1}, x^{3}, x^{3}\right)$ (Principia, Newton 1642-1727) is not unique and the choosing of coordinates is arbitrary.

Translation. The coordinates $\mathbf{x}$ may be changed, e.g., by as a matter of convenience, and the translated coordinates equal:

$$
\mathbf{x}^{\prime}=\mathbf{x}+\mathbf{x}_{\mathbf{0}}
$$

The translated diffusion velocity satisfies Eqs. (70) and $(71)$. The same is true for a translated time:

$$
t^{\prime}=t+t_{0} \text {. }
$$

This property is referred to as active translational symmetry in the space-time continuum and the procedure given by Eqs. (72) and (73). A further transformation specifies the coordinates of a physical system moving relative to an observer with velocity $v_{0}$ :

$$
\mathbf{x}^{\prime}=\mathbf{x}+v_{0} t
$$

Again, the translated diffusion velocity satisfies Eqs. (70) and (71). Including rotation, the full set of all transformations is called the Galilei group defined by successive transformations:

$$
\begin{gathered}
x^{\prime i}=R_{j}^{i} x^{j}+v_{0}^{i} t+x_{0}^{i}, \\
t^{\prime}=t+t_{0},
\end{gathered}
$$

where $R_{j}^{i}=\cos \theta \delta_{i j}+(1-\cos \theta) \hat{\theta}_{i} \hat{\theta}_{j}+\sin \theta \varepsilon_{i j k} \hat{\theta}_{k} ; \quad \hat{\theta}_{i}$ denotes a directional unit vector of the rotation axis [34]. The repeated spatial index in Eq. (75) denotes a sum 1 to 3. Following Newton,

\begin{tabular}{|c|}
\hline Deleted: 72 \\
\hline Deleted: 73 \\
\hline Deleted: (70) \\
\hline Deleted: (71) \\
\hline Deleted: (71) \\
\hline Deleted: (72) \\
\hline Deleted: 73 \\
\hline Deleted: 74 \\
\hline Deleted: (72) \\
\hline Deleted: (73) \\
\hline Deleted: (73) \\
\hline Deleted: (74) \\
\hline Deleted: 74 \\
\hline Deleted: 75 \\
\hline Deleted: (70) \\
\hline Deleted: (71) \\
\hline Deleted: (71) \\
\hline Deleted: (72) \\
\hline Deleted: 75 \\
\hline Deleted: 76 \\
\hline Deleted: 76 \\
\hline Deleted: 77 \\
\hline Deleted: (75) \\
\hline Deleted: (76) \\
\hline Deleted: (70) \\
\hline Deleted: (71) \\
\hline Deleted: (71) \\
\hline Deleted: (72) \\
\hline Deleted: (34) \\
\hline Deleted: (35) \\
\hline
\end{tabular}
the all coordinate frames in which diffusion velocities and mass conservation have a simple form given by Eqs. (70) and (71) are called inertial frames.

Generalized method vs. Darken. We show now that when the Darken simplified conditions are valid Eq. (34) results in the Darken expression. Kirkendall experimentally [21], Darken theoretically [15] and one of the authors in multicomponent solid mixtures [16] have shown that diffusion fluxes are locally not balanced and their sum depends on time and position, i.e., $\operatorname{div}\left(\sum_{i=1}^{r} c_{i} \Omega_{i} v_{i}^{d}\right) \neq 0$ and the law of the lattice sites conservation does not exist [19]. Consequently, 
the volume continuity implies that the Darken velocity, $v^{D}$, has to be generated during the interdiffusion process. We consider pure diffusion in the incompressible, ideal solid solution. In such a case:

1. The deformation velocity equals zero $\left(v^{\sigma}(t, x)=0\right)$;

2. Translation depends on time only $\left(v^{t r}=v^{t r}(t)\right)$;

3. Molar volumes are constant and equal $\Omega=\Omega_{i}=$ const for every component $(c=$ const $)$;

4. Activity coefficients equal unity $\left(a_{i}=c_{i}\right)$;

5. External forcing is negligible $\left(\operatorname{grad} V^{e x t} \cong 0\right)$.

From Eq. (31) it follows that:

$$
\operatorname{div}\left(\sum_{i=1}^{r} c_{i} \Omega_{i} v^{D}+\sum_{i=1}^{r} c_{i} \Omega_{i} v_{i}^{d}\right)=\operatorname{div}\left(c \Omega v^{D}+\sum_{i=1}^{r} c_{i} \Omega_{i} v_{i}^{d}\right)=0
$$

where the Darken drift velocity is the mixture velocity generated by diffusion.

In such a case, the term that describes unbalanced chemical potentials, Eq. (44), vanishes:

$$
\sum_{i=1}^{\mathrm{r}} c_{i} \operatorname{grad} \mu_{i}^{c h}=\sum_{i=1}^{\mathrm{r}} c_{i} R T \operatorname{grad} \ln a_{i} \stackrel{a_{i}=c_{i}}{=} R T \sum_{i=1}^{\mathrm{r}} \operatorname{grad} c_{i}=R T \operatorname{grad} c=0
$$

and the centre of mass position is not affected by diffusion, Eqs. (50) and (78): $\left.\rho \frac{\mathrm{D} v^{m}}{\mathrm{D} t}\right|_{v^{m}}=0$

From Eq. (77) the Darken velocity equals [15]:

$$
v^{D}(t, x)=-\sum_{i=1}^{r} c_{i} \Omega_{i} v_{i}^{d}=-\frac{1}{c} \sum_{i=1}^{r} c_{i} v_{i}^{d}=-\sum_{i=1}^{r} N_{i} v_{i}^{d}
$$

Thus, we have proved the identity of the presented and Darken methods when Darken constraints are valid. The volume continuity law defines the lattice-fixed reference frame for diffusion and will allow proving the uniqueness of the Matano surface in multicomponent systems [35].

\section{SUMMARY}

We have shown that in the multicomponent systems the fluxes and velocities of the local centre of mass, $v^{m}$, composition, $v^{M}$ and volume, $v^{V}$, are defined by densities and velocities of diffusion and drift:

$$
\begin{aligned}
& \rho v^{m}=\sum_{i=1}^{r}\left(\rho_{i} v^{d r i f t}+\rho_{i} v_{i}^{d}\right) \quad \text { and } \quad v^{m}:=v^{d r i f t}+\sum_{i=1}^{r} \frac{M_{i}}{M} N_{i} v_{i}^{d}, \\
& c v^{M}=\sum_{i=1}^{r}\left(c_{i} v^{d r i f t}+c_{i} v_{i}^{d}\right) \quad \text { and } \quad v^{M}:=v^{d r i f t}+\sum_{i=1}^{r} N_{i} v_{i}^{d}, \\
& c \Omega v^{V}=\sum_{i=1}^{r}\left(c_{i} \Omega_{i} v^{d r i f t}+c_{i} \Omega_{i} v_{i}^{d}\right) \quad \text { and } \quad v^{V}:=v^{d r i f t}+\sum_{i=1}^{r} \frac{\Omega_{i}}{\Omega} N_{i} v_{i}^{d},
\end{aligned}
$$

where $\Omega c$ and $\Omega_{i} c_{i}$ are the total $(\Omega c \equiv 1)$ and partial volume densities.

\begin{tabular}{|l|}
\hline Deleted: (31) \\
\hline Deleted: (32) \\
\hline Deleted: 77 \\
\hline Deleted: 78 \\
\hline
\end{tabular}

\begin{tabular}{|l|}
\hline Deleted: (44) \\
\hline Deleted: (45) \\
\hline Formatted: English (U.S.) \\
\hline $\begin{array}{l}\text { Formatted: English (U.S.), Check } \\
\text { spelling and grammar }\end{array}$ \\
\hline Formatted: English (U.S.) \\
\hline Formatted: English (U.S.) \\
\hline Formatted: English (U.S.), Check \\
spelling and grammar \\
\hline Formatted: English (U.S.) \\
\hline Deleted: 78 \\
\hline Deleted: 79 \\
\hline Deleted: (50) \\
\hline Deleted: $(51)$ \\
\hline Deleted: (78) \\
\hline Deleted: (79) \\
\hline Deleted: $(77)$ \\
\hline Deleted: $(78)$ \\
\hline
\end{tabular}

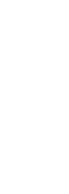


Acknowledgments. MATERA ERA-NET EU project (MASTRA) is acknowledged for financial support,

Basing our analysis on the Euler's and Lagrange theorems we derived the formula of volume density conservation, i.e., the volume continuity equation. This fundamental formula defines the volume-fixed frame of reference in the multicomponent, solid, gas and liquid solutions. The volume continuity equation allows the defining of the drift velocity, i.e., the coordinate axes for diffusion:

$$
\operatorname{div}\left(\sum_{i=1}^{r} c_{i} \Omega_{i} v_{i}\right)=\operatorname{div}\left(v^{d r i f t}+\sum_{i=1}^{r} c_{i} \Omega_{i} v_{i}^{d}\right)=0,
$$

where the diffusion velocity is given by an appropriate constitutive expression.

The volume-fixed frame of reference is an inertial frame. It allows the use of the NavierLamé equation of mechanics of solids. Proposed modifications of Navier-Lamé and energy conservation equations are self-consistent with the literature for solid-phase continua dating back to the classical experiments of Kirkendall and their interpretation by Darken. No basic changes are required in the foundations of linear irreversible thermodynamics except recognizing the need to add volume density to the usual list of extensive physical properties undergoing transport in every continuum.

The local momentum density depends on the diffusion of mass as well as on all other transport processes, e.g., on the Darken velocity. The balance of momentum, Eq. (50), fulfills the condition, that the local acceleration of the body depends on its mass, not on its internal energy and that the local centre of mass position is not affected by diffusion.

We have proved the identity of the presented and Darken methods when Darken constraints are valid.

\section{REFERENCES}

[1] H. Brenner, Phys. A 370 (2006) p. 190.

[2] H. Brenner, Phys. A 349 (2005) p. 60.

[3] J. R. Bielenberg and H. Brenner, Phys. A, 356 (2005) p. 279.

[4] Y. Liang, R. M. Richter and L. Chamberlin, Geochim. and Cosmochim. Acta 61 (1997) p. 5295.

[5] D. Bedeaux, S. Kjelstrup and H. Ch. Öttinger, Phys. A 371 (2006) p. 177.

[6] H. C. Öttinger, Beyond Equilibrium Thermodynamics, Wiley, New Jersey, 2005.

[7] S. R. De Groot, P. Mazur, Non-Equilibrium Thermodynamics, North-Holland, Amsterdam, 1962.

[8] G. D. C. Kuiken, Thermodynamics of Irreversible Processes: Applications to Diffusion and Rheology, Wiley, New York, 1994.

[9] C. Truesdell, Amer. Math. Monthly 60 (1953) p. 445.

[10] G. B. Stephenson, Acta Metall. 36 (1988) p. 2663.

[11] Jean Philibert, Atom movements, Diffusion and mass transport in solids, S. J. Rothman, tr, EDP Sciences Editions, Les Ulis 1991, Appendix 1.

[12] M. Danielewski and W. Krzyżański, Phys. Stat. Sol. A 145 (1994) p. 351.

[13] L. D. Landau and E. M. Lifshitz: Fluid Mechanics, 2nd ed. Butterworth-Heinemann, Oxford, 1987.

[14] P. Kofstad and M. Liu, Phys. Rev. E 58 (1998) p. 5535.

[15] L. S. Darken, Trans. A.I.M.E. 174 (1948) p. 184.

[16] K. Holly and M. Danielewski, Phys. Rev. B Vol. 50 (1994) p. 13336.

[17] T. Shimozaki and M. Onishi, Trans. of the Japan Inst. of Metals 24 (1983) p. 301.

[18] M. Danielewski and B. Wierzba, J. Phase Equlib. and Diff. 26 (2005) p. 573. 
[19] M. Danielewski and B. Wierzba, Phys. A 387 (2008) p. 745

[20] R. Haase, Thermodynamics of Irreversible Processes, Addison-Wesley: Reading, 1969.

[21] O. Kirkendall, Trans AIME 147 (1942) p. 104.

[22] W. Nernst, Z. Phys. Chem. 4 (1889) p. 129.

[23] M. Planck, Ann. Phys. Chem. 40 (1890) p. 561.

[24] J. Frenkel, Z. f. Physik, 26 (1924) p. 117.

[25] J. Frenkel, Z. f. Physik, 35 (1926) p. 652

[26] W. Schottky, H. Ulich and C. Wagner, Thermodynamik, die Lehre von den Kreisprozessen, den physikalischen und chemischen Veränderungen und Gleichgewichten, Verlag Julius Springer, Berlin 1929.

[27] W. Schottky, Z. phys. Chemie B29 (1935) p. 335.

[28] L. Bonpunt, N-B Chanh and Y. Haget, J. Phys. C: Solid State Phys. 18 (1985) p. 5697.

[29] A. J. Chorin and J. E. Mardsen: A Mathematical Introduction to Fluid Mechanics Springer-Verlag, New York, 1990.

[30] R. J. Borg and G. J. Dienes, The Physical Chemistry of Solids, Academic Press, New York 1992, p. 571.

[31] T. Chaundy, The Differential Calculus, Oxford, 1935, p. 157.

[32] A. E. Fick, Prog. Ann. 94 (1855) p. 59.

[33] I. Prigogine, Nature 246 (1973) p. 67.

[34] H. Kleinert, Multivalued Fields in Condensed Matter, Electromagnetism, and Gravitation, World Sci. Publ. Co., Singapore 2007.

[35] C. Matano, Jpn. J. Phys. 8 (1933) p. 109. 
English (U.S.)

Page 9: [1] Formatted

ScholarOne

11/6/2008 3:33:00 AM

English (U.S.), Check spelling and grammar

Page 9: [1] Formatted

ScholarOne

11/6/2008 3:33:00 AM

English (U.S.)

Page 9: [2] Formatted ScholarOne

11/6/2008 3:33:00 AM

Font color: Auto, English (U.S.)

Page 9: [2] Formatted ScholarOne

11/6/2008 3:33:00 AM

Font color: Auto, English (U.S.), Check spelling and grammar

\begin{tabular}{|c|c|c|}
\hline Page 9: [2] Formatted & ScholarOne & $11 / 6 / 2008$ 3:33:00 AM \\
\hline \multicolumn{3}{|c|}{ Font color: Auto, English (U.S.) } \\
\hline Page 9: [3] Formatted & Marek Danielewski & $11 / 6 / 2008$ 8:58:00 AM \\
\hline \multicolumn{3}{|c|}{ Font color: Auto, English (U.S.) } \\
\hline Page 9: [3] Formatted & Marek Danielewski & $11 / 6 / 2008$ 8:58:00 AM \\
\hline \multicolumn{3}{|c|}{ Font color: Auto, English (U.S.), Check spelling and grammar } \\
\hline Page 9: [3] Formatted & Marek Danielewski & $11 / 6 / 2008$ 8:58:00 AM \\
\hline Font color: Auto, En & & \\
\hline
\end{tabular}

\begin{tabular}{ccc}
\hline Page 9: [4] Formatted & Marek Danielewski & 11/6/2008 8:58:00 AM \\
English (U.S.) &
\end{tabular}

Page 9: [4] Formatted Marek Danielewski

$11 / 6 / 2008$ 8:58:00 AM

English (U.S.), Check spelling and grammar

\begin{tabular}{ll}
\hline Page 9: [4] Formatted & Marek Danielewski \\
English (U.S.) & 11/6/2008 8:58:00 AM
\end{tabular}

\begin{tabular}{lcc}
\hline Page 9: [5] Formatted & ScholarOne & $11 / 6 / 2008$ 3:33:00 AM \\
English (U.S.) &
\end{tabular}

Page 9: [5] Formatted ScholarOne

11/6/2008 3:33:00 AM

English (U.S.), Check spelling and grammar

\begin{tabular}{|c|c|c|}
\hline \multicolumn{3}{|l|}{$\begin{array}{l}\text { Page 9: [5] Formatted } \\
\text { English (U.S.) }\end{array}$} \\
\hline Page 9: [6] Formatted & Marek Danielewski & 11/6/2008 8:58:00 AM \\
\hline \multicolumn{3}{|l|}{ English (U.S.) } \\
\hline Page 9: [6] Formatted & Marek Danielewski & 11/6/2008 8:58:00 AM \\
\hline \multicolumn{3}{|c|}{ English (U.S.), Check spelling and grammar } \\
\hline $\begin{array}{l}\text { Page 9: [6] Formatted } \\
\text { English (U.S.) }\end{array}$ & Marek Danielewski & 11/6/2008 8:58:00 AM \\
\hline
\end{tabular}

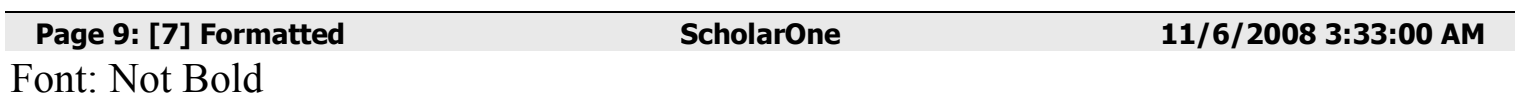

\begin{tabular}{|c|c|c|}
\hline Page 9: [7] Formatted & ScholarOne & 11/6/2008 3:33:00 AM \\
\hline
\end{tabular}

\begin{tabular}{lll}
\hline Page 9: [7] Formatted & ScholarOne & $11 / 6 / 2008$ 3:33:00 AM \\
Font: Not Bold & &
\end{tabular}


Font: Not Bold

Page 9: [8] Formatted Marek Danielewski

11/6/2008 8:58:00 AM

Font: Not Bold, Check spelling and grammar

Page 9: [8] Formatted Marek Danielewski

11/6/2008 8:58:00 AM

Font: Not Bold

Page 9: [9] Formatted

ScholarOne

11/6/2008 3:33:00 AM

Font: Not Bold

Page 9: [9] Formatted ScholarOne

11/6/2008 3:33:00 AM

Font: Not Bold, Check spelling and grammar

\begin{tabular}{|c|c|c|}
\hline Page 9: [9] Formatted & ScholarOne & 11/6/2008 3:33:00 AM \\
\hline \multicolumn{3}{|c|}{ Font: Not Bold } \\
\hline Page 9: [10] Formatted & Marek Danielewski & 11/6/2008 8:58:00 AM \\
\hline \multicolumn{3}{|l|}{ Font: Not Bold } \\
\hline Page 9: [10] Formatted & Marek Danielewski & 11/6/2008 8:58:00 AM \\
\hline \multicolumn{3}{|c|}{ Font: Not Bold, Check spelling and grammar } \\
\hline Page 9: [10] Formatted & Marek Danielewski & 11/6/2008 8:58:00 AM \\
\hline Font: Not Bold & & \\
\hline
\end{tabular}

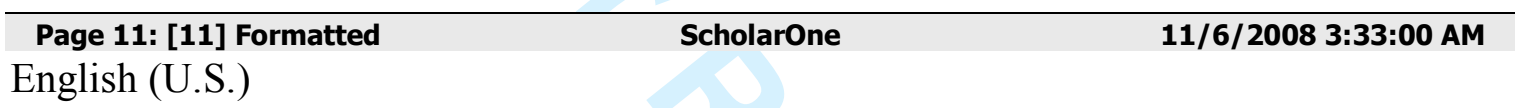

Page 11: [11] Formatted

ScholarOne

11/6/2008 3:33:00 AM

English (U.S.), Check spelling and grammar

\begin{tabular}{|c|c|c|}
\hline Page 11: [11] Formatted & ScholarOne & 11/6/2008 3:33:00 AM \\
\hline English (U.S.) & & \\
\hline
\end{tabular}

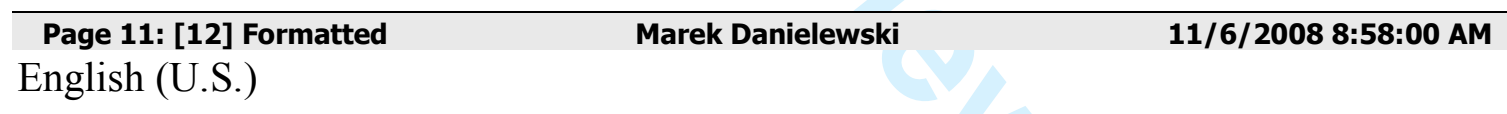

Page 11: [12] Formatted Marek Danielewski

11/6/2008 8:58:00 AM

English (U.S.), Check spelling and grammar

\begin{tabular}{lcc}
\hline $\begin{array}{l}\text { Page 11: [12] Formatted } \\
\text { English (U.S.) }\end{array}$ & Marek Danielewski & $11 / 6 / 2008$ 8:58:00 AM \\
\hline Page 11: [13] Formatted & ScholarOne & $11 / 6 / 2008$ 3:33:00 AM \\
English (U.S.) & & $11 / 6 / 2008$ 3:33:00 AM \\
\hline Page 11: [13] Formatted & ScholarOne & \\
English (U.S.), Check spelling and grammar & $11 / 6 / 2008$ 3:33:00 AM \\
\hline Page 11: [13] Formatted & ScholarOne & \\
English (U.S.) & & $11 / 6 / 2008$ 8:58:00 AM \\
\hline Page 11: [14] Formatted & Marek Danielewski \\
English (U.S.) & & \\
\hline
\end{tabular}

\begin{tabular}{lc}
\hline Page 11: [14] Formatted & Marek Danielewski \\
English (U.S.), Check spelling and grammar & 11/6/2008 8:58:00 AM \\
\hline
\end{tabular}

English (U.S.) 
English (U.S.), Check spelling and grammar

Page 11: [15] Formatted

ScholarOne

$11 / 6 / 2008$ 3:33:00 AM

English (U.S.)

English (U.S.), Check spelling and grammar

\begin{tabular}{|c|c|c|}
\hline Page 11: [16] Formatted & Marek Danielewski & $11 / 6 / 2008$ 8:58:00 AM \\
\hline \multicolumn{3}{|l|}{ English (U.S.) } \\
\hline Page 11: [17] Formatted & ScholarOne & $11 / 6 / 2008$ 3:33:00 AM \\
\hline \multicolumn{3}{|l|}{ English (U.S.) } \\
\hline Page 11: [17] Formatted & ScholarOne & $11 / 6 / 2008$ 3:33:00 AM \\
\hline \multicolumn{3}{|c|}{ English (U.S.), Check spelling and grammar } \\
\hline Page 11: [17] Formatted & ScholarOne & $11 / 6 / 2008$ 3:33:00 AM \\
\hline English (U.S.) & & \\
\hline
\end{tabular}

\begin{tabular}{|c|c|c|}
\hline Page 11: [18] Formatted & Marek Danielewski & $11 / 6 / 2008$ 8:58:00 AM \\
\hline English (U.S.) & & \\
\hline
\end{tabular}

Page 11: [18] Formatted Marek Danielewski

11/6/2008 8:58:00 AM

English (U.S.), Check spelling and grammar

\begin{tabular}{|c|c|c|}
\hline Page 11: [18] Formatted & Marek Danielewski & $11 / 6 / 2008$ 8:58:00 AM \\
\hline \multicolumn{3}{|l|}{ English (U.S.) } \\
\hline Page 11: [19] Formatted & Marek Danielewski & $11 / 6 / 2008$ 8:58:00 AM \\
\hline \multicolumn{3}{|l|}{ English (U.S.) } \\
\hline Page 11: [19] Formatted & Marek Danielewski & $11 / 6 / 2008$ 8:58:00 AM \\
\hline \multicolumn{3}{|c|}{ English (U.S.), Check spelling and grammar } \\
\hline Page 11: [19] Formatted & Marek Danielewski & $11 / 6 / 2008$ 8:58:00 AM \\
\hline \multicolumn{3}{|l|}{ English (U.S.) } \\
\hline Page 11: [20] Formatted & ScholarOne & $11 / 6 / 2008$ 3:33:00 AM \\
\hline \multicolumn{3}{|l|}{ English (U.S.) } \\
\hline Page 11: [20] Formatted & ScholarOne & $11 / 6 / 2008$ 3:33:00 AM \\
\hline \multicolumn{3}{|c|}{ English (U.S.), Check spelling and grammar } \\
\hline Page 11: [20] Formatted & ScholarOne & $11 / 6 / 2008$ 3:33:00 AM \\
\hline \multicolumn{3}{|l|}{ English (U.S.) } \\
\hline Page 11: [21] Formatted & ScholarOne & $11 / 6 / 2008$ 3:33:00 AM \\
\hline English (U.S.) & & \\
\hline
\end{tabular}

\begin{tabular}{|c|c|c|}
\hline Page 11: [21] Formatted & ScholarOne & $11 / 6 / 2008$ 3:33:00 AM \\
\hline
\end{tabular}

\footnotetext{
Page 11: [21] Formatted

ScholarOne

11/6/2008 3:33:00 AM

English (U.S.)
} 


\section{Page 11: [22] Formatted} English (U.S.)
Marek Danielewski

Marek Danielewski

Page 11: [22] Formatted English (U.S.), Check spelling and grammar

\begin{tabular}{|c|c|c|}
\hline Page 11: [22] Formatted & Marek Danielewski & $11 / 6 / 2008$ 8:58:00 AM \\
\hline \multicolumn{3}{|l|}{ English (U.S.) } \\
\hline Page 11: [23] Formatted & ScholarOne & $11 / 6 / 2008$ 3:33:00 AM \\
\hline \multicolumn{3}{|l|}{ English (U.S.) } \\
\hline Page 11: [23] Formatted & ScholarOne & $11 / 6 / 2008$ 3:33:00 AM \\
\hline \multicolumn{3}{|c|}{ English (U.S.), Check spelling and grammar } \\
\hline Page 11: [23] Formatted & ScholarOne & $11 / 6 / 2008$ 3:33:00 AM \\
\hline \multicolumn{3}{|l|}{ English (U.S.) } \\
\hline Page 11: [24] Formatted & Marek Danielewski & $11 / 6 / 2008$ 8:58:00 AM \\
\hline \multicolumn{3}{|l|}{ English (U.S.) } \\
\hline Page 11: [24] Formatted & Marek Danielewski & 11/6/2008 8:58:00 AM \\
\hline \multicolumn{3}{|c|}{ English (U.S.), Check spelling and grammar } \\
\hline Page 11: [24] Formatted & Marek Danielewski & 11/6/2008 8:58:00 AM \\
\hline English (U.S.) & & \\
\hline
\end{tabular}

